\title{
Impact of single-layer dome modelling on the critical load capacity
}

\author{
Paweł Zabojszcza ${ }^{1, *}$, Urszula Radoń $^{1}$, and Paulina Obara ${ }^{1}$ \\ ${ }^{1}$ Kielce University of Technology, Faculty of Civil Engineering and Architecture, al. Tysiąclecia \\ Państwa Polskiego 7, 25-314 Kielce, Poland
}

\begin{abstract}
In the study an attempt was made to evaluate the effect produced by the modelling of the single-layer lattice dome on its critical load capacity. The modelling concerned the means of connecting bars in a node, bars of the lattice dome, and the effect of geometric imperfections. Taking steel covers, two basic means of modelling of how bars are connected in the node can be distinguished, namely pin and rigid joints. In the study, the pin joint was SBP-1 type connector, whereas the rigid joint WABI-1 connector. In the description of bars, truss and frame elements were employed. Each element accounted for geometric nonlinearities in the Lagrange description. Regarding a frame element, the physical relationships represented the elastic behaviour of the structure with the use of the Hooke's law. With respect to the compression truss elements, a nonlinear relationship resulting from experimental investigations was additionally employed. Stability analysis of the structure was performed by means of the Finite Element Method using Abaqus and Robot Structural Analysis software. In order to obtain the load-displacement relations, the Riks arc length method was used. The analysis was focused on global modes of stability loss due to snap-through and bifurcation.
\end{abstract}

\section{Introduction}

Single-layer lattice domes are often used in many modern engineering structures. The key advantages offered by these structures include low dead load combined with relatively high critical load capacity. In the design of such structures stability analysis plays a vital role [1-5]. Stability loss in bar structures can be global or local in character. In the first case, bifurcation of the balance position or node snap-through can occur, the other case additionally involves buckling or lateral torsional buckling of individual bars of the system.

In literature, qualitatively different means of estimating the critical load capacity of lattice domes can be found. In the study [6], Głąbik gave formulas for the critical load capacity of a triangular mesh dome. In the formula, the slenderness of the bars and initial node deviation in assembly were accounted for. In the study [7], Bródka et al. estimated critical load capacity of a structure constructed from bars according to the Prandtl model using a method of successive approximations. Rządkowski, Kowal, Słowik, Wawszczak in

${ }^{*}$ Corresponding author: zabojszcza.pawel@gmail.com 
studies [8,9] emphasised effect of geometric imperfections of bars, especially of their axes, on the critical load capacity. It can be even a few times lower than the critical load capacity of the dome with perfect geometry. Experimental investigations on the previously prepared models were frequently used $[8,9]$.

In the paper an attempt was made to carry out numerical simulations by means of the commonly available software. The simulations concerned the assessment of the effect of single-layer lattice dome modelling on its critical load capacity. Different types of bar connection in a node, means of modelling dome bars and geometric imperfections were taken into account.

\section{Means of modelling bars in the nodes of the single-layer lattice domes}

Joints and nodes are necessary to transfer actions, to create constraints in the elements, or between them and to transfer external forces. Components of joints and nodes are susceptible to rupture, pressure, cut, local stability loss or shear [10]. In steel covers, basically two ways of bar connection in nodes can be differentiated, namely pin and rigid joints. In the study, the pin joint was SBP-1 type connector, whereas the rigid joint WABI-1 connector.

In 1988, Schlaich-Bergermann \& Partner, Stuttgart, Germany, published the basic principles of a reticulated structure with a splice connector, whose first implementation SBP-1 is shown in Figure 1. The node connector consists of two flat plates connected by a single central bolt. Simultaneously, a clamp for cable bracings can be connected to the node through the central bolt. Each structural member is connected to the horizontal splice plates by two or more bolts in single shear. The central bolt allows for an easy adjustment of the horizontal angle between the structural members. Vertical angles can be accommodated by means of folding the splice plates. Twist angles can be adjusted only in a highly limited range of imperfections. In consequence of the small section height of the splice plates, this node connector can transfer limited bending moments only [11].
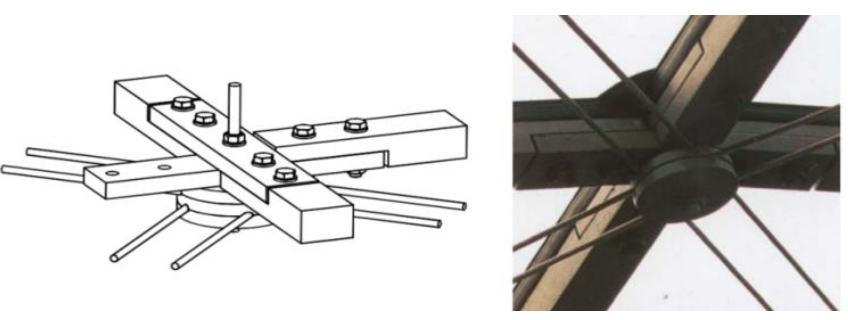

Fig. 1.Splice Connector SBP-1 [11].

The node, shown in Figure 2, is a welded end-face connector WABI-1, which was developed by Waagner-Biro AG, Vienna, Austria, for the courtyard roof of the British Museum in London. The node consists of a star-shaped plate with 5 or 6 arms. Each arm runs between adjacent structural members. These nodes are made of thick plates by cutting perpendicular to the plate surface. The end-faces of the structural members have a double mitre cut to match with the corresponding node gap between adjacent arms. The thickness of the node plate is less than the height of the connected structural members. Both, top and bottom surface of the node plates are connected to the members by fillet welds, the side surfaces are connected by butt welds. Horizontal, vertical and twist angles of structural members at this node can be accommodated by the geometry of the double mitre cuts at the end of the members. High bending moments, up to the full member strength, can be transferred [11]. 

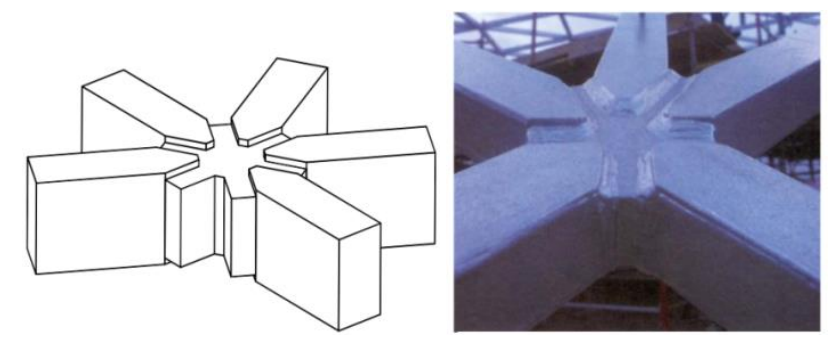

Fig. 2. End-Face Connector WABI-1 [11].

\section{Means of modelling bars and the numerical techniques used}

In the study, two attempts to bar modelling, by means of truss and frame elements were considered. Both models took into account geometric nonlinearities in the Lagrange description. Applying the frame element, the physical relationships represented the elastic behaviour of the structure with the use of Hooke's law. Regarding the compressive truss elements, a nonlinear relationship resulting from experimental investigations was additionally employed.

The sources of the nonlinear relations $\underline{\sigma}=f(\underline{\varepsilon})$ are, apart from strictly material features, also geometrical imperfections. In this analysis, differential constitutive relations were neglected, these were generated for an entire element (i.e. for individual bars). This approach does not allow to separate the material and geometrical imperfections. The experiments were carried out using bars 163 to $572 \mathrm{~mm}$ in length. Therefore, it was of utmost importance to properly interpret the scale effect. The solution was reached creating a dimensionless load-displacement relation (RLD) due to imperfect compressed bar (Fig. 3). The parameters of the RLD were derived using experimental test results presented by Kowal and Radoń [12].

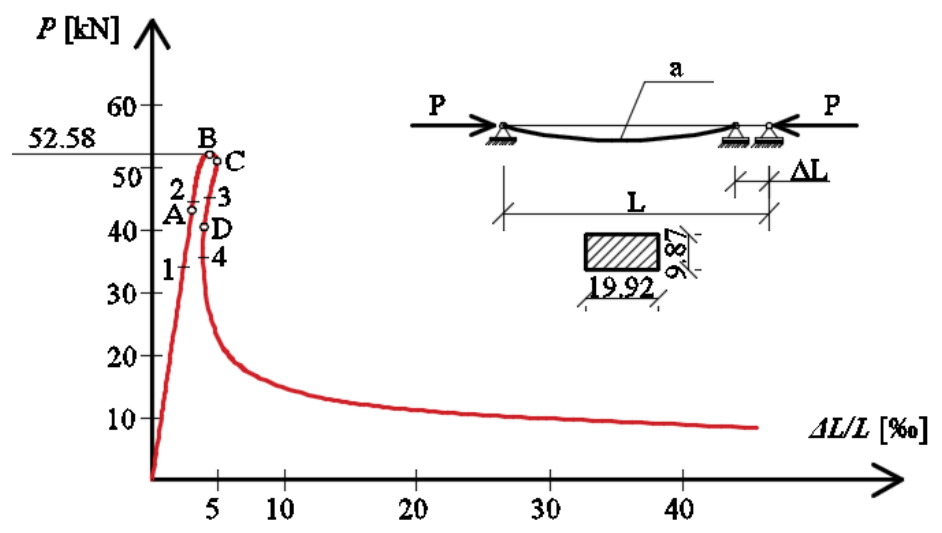

Fig. 3.Example of a RLD due to a bar with imperfections.

Stability analysis of the structure was performed with the FEM-based software: Abaqus and Robot Structural Analysis. In order to obtain the load-displacement relation, the Riks arc length method was used [13]. Four years after the arc length method was proposed by Riks, Crisfield came up with an alternative to that method. The latter was employed in many commercial FEM programs [14]. Another variant of the constant arc length method, similar to that developed by Crisfield, was put forward by Ramm. It was termed a modified Riks-Wempner method [15]. 


\section{Numerical results}

A lattice dome consisting of 49 nodes and 120 elements (Fig. 4) was analysed in the paper. The dome geometry is shown in Table 1. The elements of the structure made of RO101.6x6 steel pipes of yield point $f_{Y}=235 \mathrm{MPa}$ and Young's modulus $E=210 \mathrm{GPa}$. One-parameter nodal load applied in every node was taken into account. In the study, the determination of the critical load capacity of the lattice dome was performed using the following variants:

- Variant I - geometrically non-linear truss model with linear physical relationships,

- Variant II - geometrically and physically non-linear truss model,

- Variant III -geometrically non-linear truss model with linear physical relationships, taking into account geometric imperfections of the bars,

- Variant IV -geometrically non-linear frame model with linear physical relationships,

- Variant V-geometrically non-linear frame model with linear physical relationships, taking into account geometric imperfections of the bars.

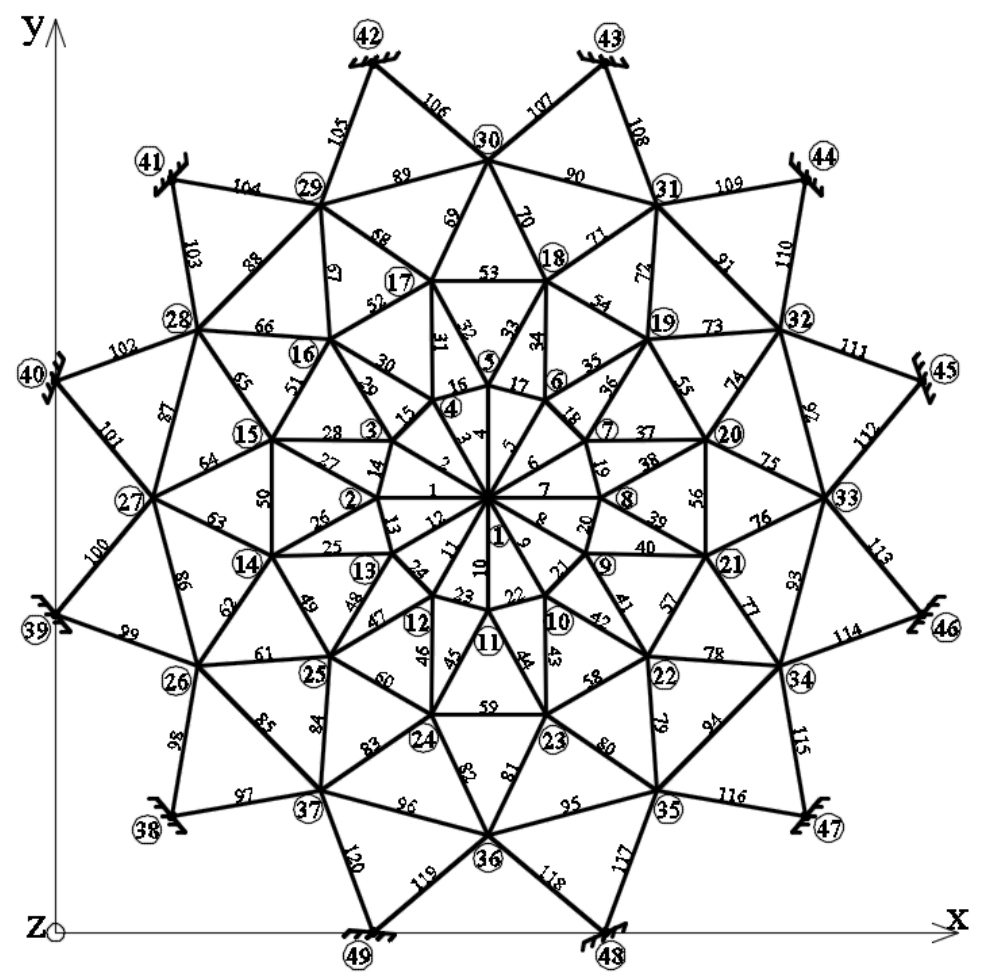

Fig. 4. Mesh of the lattice dome.

Table 1. Geometry of the lattice dome.

\begin{tabular}{|c|c|c|c|c|c|c|c|c|c|c|c|}
\hline $\begin{array}{c}\text { No. } \\
\text { of } \\
\text { node }\end{array}$ & $\mathrm{x}[\mathrm{m}]$ & $\mathrm{y}[\mathrm{m}]$ & $\begin{array}{c}\mathrm{z} \\
{[\mathrm{m}]}\end{array}$ & $\begin{array}{c}\text { No. } \\
\text { of } \\
\text { node }\end{array}$ & $\mathrm{x}[\mathrm{m}]$ & $\mathrm{y}[\mathrm{m}]$ & $\begin{array}{c}\mathrm{z} \\
{[\mathrm{m}]}\end{array}$ & $\begin{array}{c}\text { No. } \\
\text { of } \\
\text { node }\end{array}$ & $\mathrm{x}[\mathrm{m}]$ & $\mathrm{y}[\mathrm{m}]$ & $\begin{array}{c}\mathrm{z} \\
{[\mathrm{m}]}\end{array}$ \\
\hline 1 & 14.489 & 14.489 & 4.50 & 18 & 16.430 & 21.733 & 3.40 & 34 & 24.232 & 8.864 & 1.80 \\
\hline 2 & 10.739 & 14.489 & 4.15 & 19 & 19.792 & 19.792 & 3.40 & 35 & 20.114 & 4.746 & 1.80 \\
\hline 3 & 11.241 & 16.364 & 4.15 & 20 & 21.733 & 16.430 & 3.40 & 36 & 14.489 & 3.239 & 1.80 \\
\hline 4 & 12.614 & 17.736 & 4.15 & 21 & 21.733 & 12.548 & 3.40 & 37 & 8.864 & 4.746 & 1.80 \\
\hline 5 & 14.489 & 18.239 & 4.15 & 22 & 19.792 & 9.186 & 3.40 & 38 & 3.882 & 3.882 & 0.0 \\
\hline 6 & 16.364 & 17.736 & 4.15 & 23 & 16.430 & 7.244 & 3.40 & 39 & 0.0 & 10.607 & 0.0 \\
\hline
\end{tabular}




\begin{tabular}{|c|c|c|c|c|c|c|c|c|c|c|c|}
\hline 7 & 17.736 & 16.364 & 4.15 & 24 & 12.548 & 7.244 & 3.40 & 40 & 0.0 & 18.371 & 0.0 \\
\hline 8 & 18.239 & 14.489 & 4.15 & 25 & 9.186 & 9.186 & 3.40 & 41 & 3.882 & 25.095 & 0.0 \\
\hline 9 & 17.736 & 12.614 & 4.15 & 26 & 4.746 & 8.864 & 1.80 & 42 & 10.607 & 28.978 & 0.0 \\
\hline 10 & 16.364 & 11.241 & 4.15 & 27 & 3.239 & 14.489 & 1.80 & 43 & 18.371 & 28.978 & 0.0 \\
\hline 11 & 14.489 & 10.739 & 4.15 & 28 & 4.746 & 20.114 & 1.80 & 44 & 25.095 & 25.095 & 0.0 \\
\hline 12 & 12.614 & 11.241 & 4.15 & 29 & 8.864 & 24.232 & 1.80 & 45 & 28.978 & 18.371 & 0.0 \\
\hline 13 & 11.241 & 12.614 & 4.15 & 30 & 14.489 & 25.739 & 1.80 & 46 & 28.978 & 10.607 & 0.0 \\
\hline 14 & 7.244 & 12.548 & 3.40 & 31 & 20.114 & 24.232 & 1.80 & 47 & 25.095 & 3.882 & 0.0 \\
\hline 15 & 7.244 & 16.430 & 3.40 & 32 & 24.232 & 20.114 & 1.80 & 48 & 18.371 & 0.0 & 0.0 \\
\hline 16 & 9.186 & 19.792 & 3.40 & 33 & 25.739 & 14.489 & 1.80 & 49 & 10.607 & 0.0 & 0.0 \\
\hline 17 & 12.548 & 21.733 & 3.40 & & &
\end{tabular}

In all the analysed cases the node snap-through was a decisive mode of stability loss. For example, in variant I the linear bifurcation load reached a value of $44.897 \mathrm{kN}$, while the limit load for this case is $33.35 \mathrm{kN}$. In variant IV the linear bifurcation load reached a value of $50.52 \mathrm{kN}$, while the limit load for this case is $49.83 \mathrm{kN}$.

In Variant I, as the load grew until the limit point was reached, the most stressed element was bar 22 (Fig. 4). In Variant II, a decrease in the critical load capacity was observed. Additionally, compared to Variant I, it was accompanied by a displacement change corresponding to the load. In the studies [7,8,9], the authors clearly indicated a massive impact of imperfections on the critical load capacity of the structure. That could be seen in the model studies conducted by those researchers. For Variants III and V, an attempt was made to carry out the same numerical simulations. In the Abaqus environment, *BUCKLE* analysis was launched. It produced the structure buckling modes and the corresponding values of the critical force. Then, the perfect geometry of the bars was disturbed by means of nodal displacements computed in the previous step with the use of *IMPERFECTION* command. Next, computations were run again using *STATIC RIKS*. In both Variant III and Variant V, 5\% and 10\% values of the eigenvector of the first buckling mode were taken into account. As an example, the maximum displacement of the node number 1 in the frame structure for the first buckling mode of the structure is $\mathrm{Uz}=0.32 \mathrm{~mm}$ which means the adoption of imperfections at the level of $0.016 \mathrm{~mm}$ for $5 \%$ and $0.032 \mathrm{~mm}$ for $10 \%$. The character of the load-displacement relation that was obtained clearly indicates the occurrence of the limit point, which had a definitely lower value. In Variant IV, as the load increased until the limit point was reached, the numbers of the most stressed elements changed. Initially, that was bar 17 , and when $95 \%$ of the critical load capacity was applied, it was bar 115 (Fig. 4).

The critical load capacity values for the variants analysed in the study are summarised in Table 2. The Figures 5 and 8 show the deformation of the lattice dome for the truss model (Variant I) and the frame model (Variant IV), respectively. The descriptions of internal forces and stresses were also provided. Load-displacement path for geometrically non-linear model with linear physical relationships for truss and frame model, are show on the Figures 6 and 9, respectively. Figure 7 and Figure 10 show load-arc length path for geometrically and physically non-linear model with $5 \%$ of the value of the eigenvector of the first buckling mode for truss (Variant III) and frame (Variant V) models, respectively.

Table 2.Summary of the critical load capacity results.

\begin{tabular}{|c|c|c|c|c|c|c|}
\hline Variant I & Variant II & \multicolumn{2}{|c|}{ Variant III } & Variant IV & \multicolumn{2}{|c|}{ Variant V } \\
\hline $22251 \mathrm{~N}$ & 20241 & $5 \%$ & $10 \%$ & $1082 \mathrm{l} N$ & $5 \%$ & $10 \%$ \\
\hline $33.35 \mathrm{kN}$ & $20.34 \mathrm{kN}$ & $21.45 \mathrm{kN}$ & $17.01 \mathrm{kN}$ & $49.83 \mathrm{kN}$ & $46.33 \mathrm{kN}$ & $44.62 \mathrm{kN}$ \\
\hline
\end{tabular}




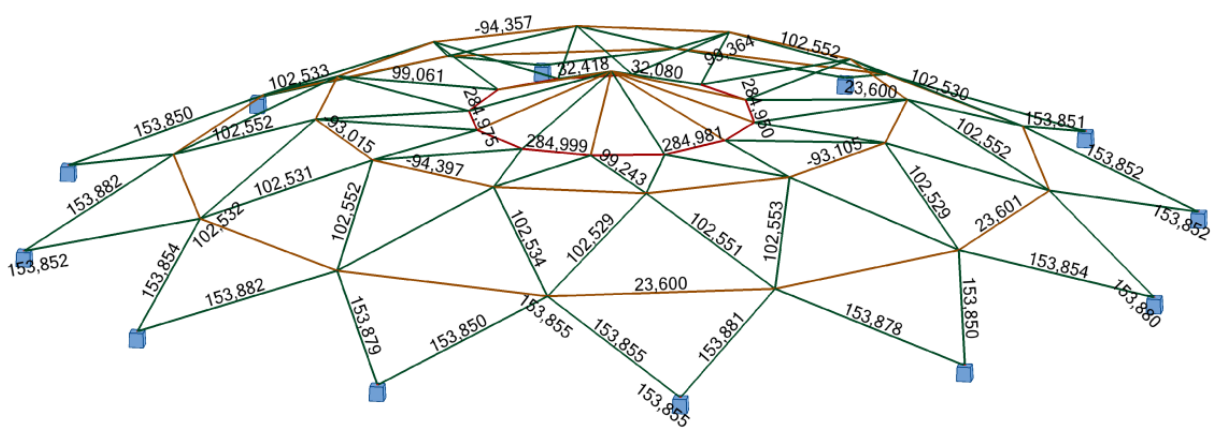

Fig. 5. Deformation of the lattice dome for the truss model with the description of axial forces in the bars at the limit point (Variant I).

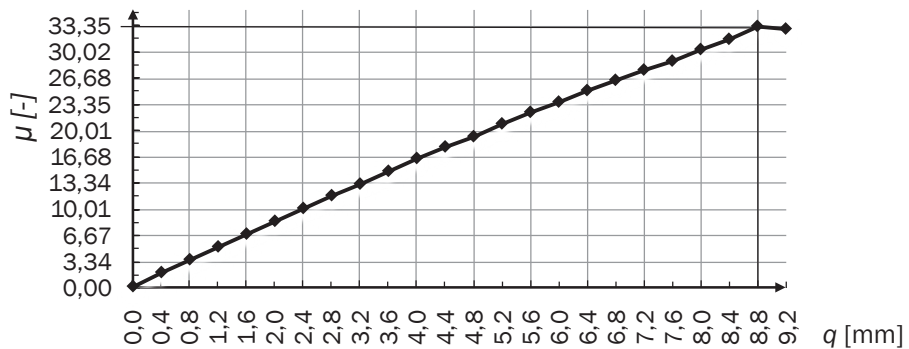

Fig. 6. Load-displacement path for geometrically non-linear truss model with linear physical relationships (Variant I).

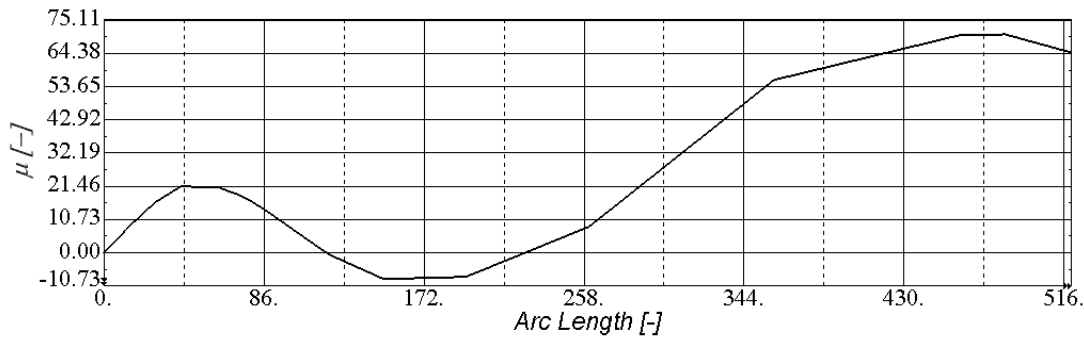

Fig. 7. Load-arc length path for geometrically non-linear truss model with $5 \%$ of the value of the eigenvector of the first buckling mode (Variant III).

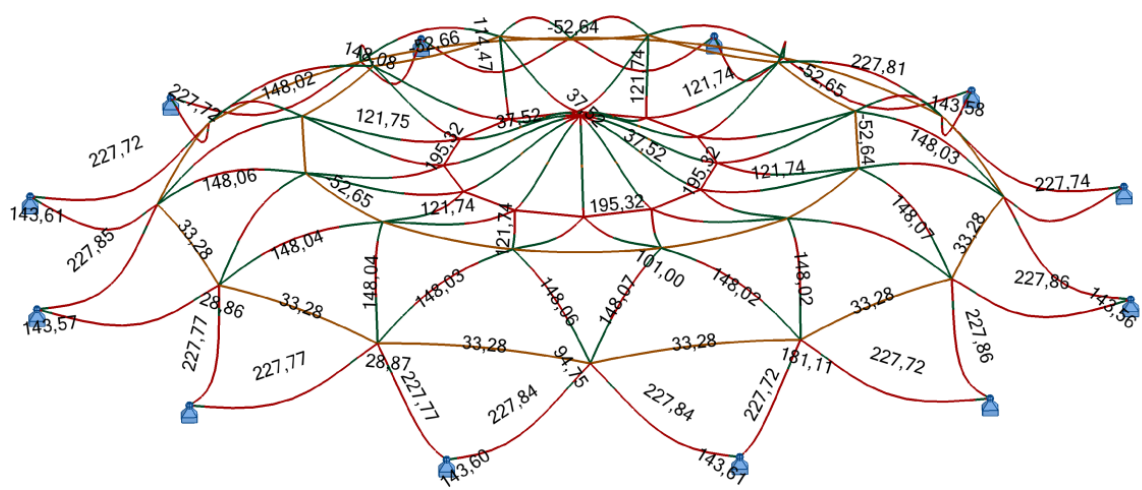

Fig. 8. Deformation of the lattice dome for the frame model with the description of the maximum stress in the bars at the limit point (Variant IV). 


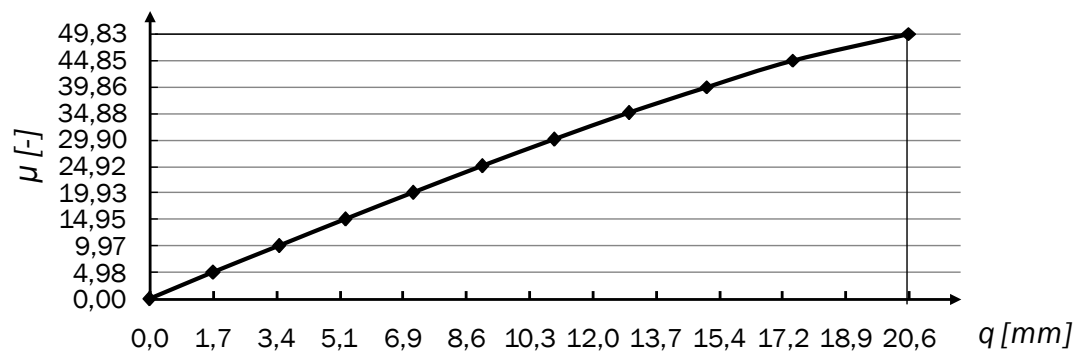

Fig. 9 . Load-displacement path for geometrically non-linear frame model with linear physical relationships (Variant IV).

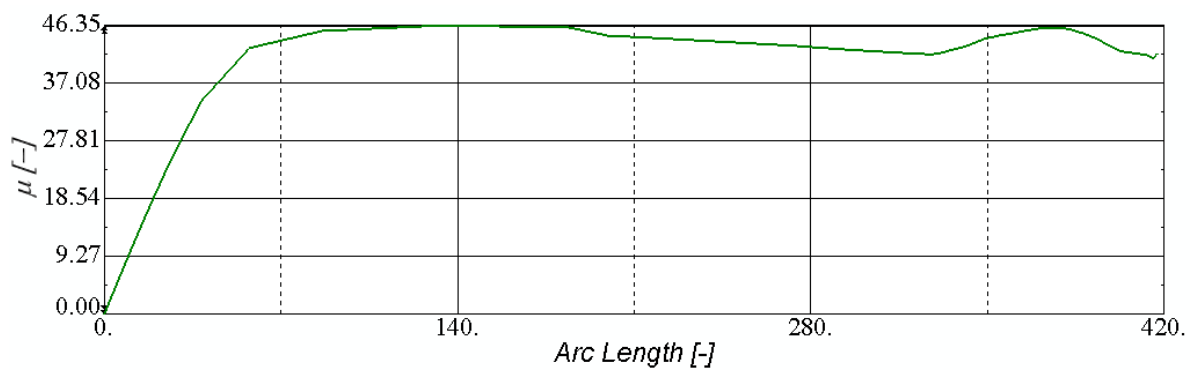

Fig. 10. Load-arc length path for geometrically non-linear frame model with $5 \%$ of the value of the eigenvector of the first buckling mode (Variant V).

\section{Summary and conclusions}

In the paper the effect of single-layer lattice dome modelling on the critical load capacity was discussed. Five variants were considered, the way of modelling was modified throughout. The modifications concerned the bar connections in nodes, bars of the lattice dome and the impact of geometric imperfections. In each case, geometric nonlinearities in the Lagrange description were taken into account. It was observed that the node snapthrough was a decisive mode of the stability loss for all the cases. In Variant I, the value of the critical load capacity, equal to $33.35 \mathrm{kN}$, was determined. In Variant II, non-linear physical relationships for the truss element were taken into account, which lowered the value of the critical load capacity to $20.34 \mathrm{kN}$. Variant III accounted for the disturbances to the perfect geometry of the bars caused by the displacement of nodes obtained from the structure buckling analysis with the use of truss elements. Numerical analysis performed with the ABAQUS program (using the *IMPERFECTION* command) showed a substantial decrease in the critical load capacity. The reductions, to the values of $21.45 \mathrm{kN}$ and $17.01 \mathrm{kN}$, constituted $5 \%$ and $10 \%$ of the value of the eigenvector of the first buckling mode, respectively. In Variant IV, a frame structure was considered, in which a linear relationship between strain and stress was utilised. The analysis demonstrated that the value of the critical load capacity was $50.58 \mathrm{kN}$. Additionally, as the load increased, a change in the most stressed elements, namely from bar no.17 to the near-support bar no. 115, was observed. Finally, in Variant V, the geometry of the frame elements was disturbed by imperfections, as it was the case with Variant III. Again, the effect of imperfections on a decrease in the critical load capacity was observed, which was $5 \%$ to $46.33 \mathrm{kN}$, and $10 \%$ to $44.62 \mathrm{kN}$. Stability analysis of the structure was performed with the Finite Element Method using Abaqus and Robot Structural Analysis software. Differences in results between software were insignificant, less than 5\%. In this paper B32 element was used for 
frame structure and T3D2 element for truss structure. The elements in the frame structure were additionally compacted 10 times.

Because of the height-to-span ratio of 0.155 , the structure under analysis is a shallow dome. Structures of this type are characterised by strong nonlinearity, consequently they are extremely susceptible to stability loss resulting from the node snap-through. In such a case, it is not sufficient to carry out the analysis of initial stability. It is necessary to perform a nonlinear stability analysis that allows the determination of limit points related to that mode of stability loss.

\section{References}

1. J. Marcinowski, Stability of elastic structures, Dolnośląskie Wydawnictwo Edukacyjne (2017) [in Polish]

2. Z. Waszczyszyn, Cz. Cichoń, M. Radwańska, Stability of Structures by Finite Element Methods, Elsevier (1994)

3. U. Pawlak, M. Szczecina, Dynamic eigenvalue of concrete slab road surface, IOP Conf. Series: Materials Science and Engineering 245 (2017)

4. P. Obara, W. Gilewski, Dynamic stability of moderately thick beams and frames with the use of harmonic balance and perturbation methods, Bulletin of The Polish Academy of Sciences: Technical Sciences, 64, 4,739-750 (2016)

5. W. Mochocki, P. Obara, U. Radoń, P. Zabojszcza, Effect of single-layer truss dome geometry on critical load capacity, Structure and Environmental, 93, 152-164 (2017)

6. J. Głąbik, Critical load in pin-jointed single-layer lattice domes, Doctoral thesis, Politechnika Śląska (1970) [in Polish]

7. J. Bródka, I. Czmoch, M. Giżejowski, J. Marczewski, Ultimate capacity of steel lattice dome, Inżynieria i Budownictwo, 1, 21-24 (1983) [in Polish]

8. Z. Kowal, J. Słowik, W. Wawszczak, Principles of the design of bar-rib domes, Inżynieria i Budownictwo, 7, 247-250 (1992) [in Polish]

9. J. Rządkowski, Limit load capacity in single-layer lattice domes loaded at nodes, Inst. Bud. Pol. Wrocławskiej (1984) [in Polish]

10. J. Bródka, A. Kozłowski, Design and computations of joints and nodes of steel structures, PWT, T.1 (2013)[in Polish]

11. S. Stephan, J. Sanchez-Alvarez, K. Knebel, Reticulated Structures on Free-Form Surfaces, Stahlbau (2004)

12. Z. Kowal, U. Radoń, Proposition of a constitutive model of compressed rods for calculating the limit bearing capacity of real rod constructions, Inżynieria i Budownictwo, 12, 679-683 (1995)[in Polish]

13. E. Riks, An incremental approach to the solution of snapping and buckling problems, Int. J. Solids Struct., 15, 529-551 (1979)

14. M. A. Crisfield, A fast incremental/iterative solution procedure that handles snapthrough, Comput. Struct.,13, 55-62 (1981)

15. E. Ramm, Strategies for tracing the non-linear response near limit points. Nonlinear Finite Element Analysis in Structural Mechanics, 68-89, Springer (1981) 